\title{
Uniformly dispersed Pd nanoparticles on nitrogen-doped carbon nanospheres for aerobic benzyl alcohol oxidation
}

\author{
Yan Hao, Shuai Wang, Qiang Sun, Lei Shi, An-Hui Lu* \\ State Key Laboratory of Fine Chemicals, Department of Chemical Engineering, Dalian University of Technology, Dalian 116024, Liaoning, China
}

\section{A R T I C L E I N F O}

Article history:

Received 6 November 2014

Accepted 22 December 2014

Published 20 April 2015

\section{Keywords:}

Palladium

Carbon nanosphere

Alcohol oxidation

Recyclability

\begin{abstract}
A B S T R A C T
Maintaining the dispersion and stability of supported metals is still an important issue for solid catalysts that suffer from aggregation or leaching. We report an easy procedure for the preparation of Pd nanoparticles supported on carbon nanospheres by the direct pyrolysis of the metal precursor impregnated on polybenzoxazine-based polymer nanospheres. The complexation interaction between the metal and support was beneficial for the dispersion and stability of the Pd nanoparticles. Pd nanoparticles with an average size of $3 \mathrm{~nm}$ were uniformly dispersed on the carbon nanospheres after a thermal treatment at $500{ }^{\circ} \mathrm{C}$ under argon flow. The catalyst was evaluated for aerobic benzyl alcohol oxidation under mild conditions without using a base additive. In order to get mostly outer surface Pd nanoparticles, the catalyst preparation conditions were investigated by varying the metal loading and loading time. The highest catalytic activity reached a TOF of $690 \mathrm{~h}^{-1}$ when the catalyst was prepared under the optimized conditions. The catalyst also showed good recyclability and can be easily regenerated by calcination at $200^{\circ} \mathrm{C}$.
\end{abstract}

(C) 2015, Dalian Institute of Chemical Physics, Chinese Academy of Sciences. Published by Elsevier B.V. All rights reserved.

\section{Introduction}

Benzaldehyde is an important intermediate in organic synthesis which is widely used in cosmetics, perfumes, food, and the pharmaceutical industry [1]. The selective oxidation of benzyl alcohol to benzaldehyde, especially using oxygen or air as oxidant under mild reaction conditions, is one of the important routes for its mass production to meet the requirements of green chemistry [2-4]. Nanocatalysts are considered a bridge between homogeneous and heterogeneous catalysts, and provide a catalytic platform for benign oxidation under mild reaction conditions [5,6]. Pd nanocatalysts, especially with a small and uniform size, have attracted attention in alcohol oxidation due to excellent catalytic performances [7-10]. However, small metal nanoparticles tend to aggregate during thermal annealing and can be leached during reaction, which is a major cause of catalyst deterioration [11,12]. Thus, there is a need for the design of Pd nanocatalysts with high dispersion and excellent activity and stability for both economic and environmental reasons.

For Pd nanoparticles as catalyst for benzyl alcohol oxidation, various catalyst supports including alumina [13,14], ceria [15], carbon [16], and silica [17] have been intensively investigated. Among these, carbon materials have the advantages of chemical inertness, good thermal stability, and easy recycling of metals [18]. In particular, they exhibit good adsorption of aromatics from aqueous solution due to their high surface area and $\pi-\pi$ interaction [19-22]. Thus, carbon materials are good supports for liquid phase benzyl alcohol oxidation, particularly when water is used as the solvent, because carbon materials can concentrate the reactant from the water phase, which consequently enhance the reaction rate. However, aggregation or

\footnotetext{
* Corresponding author. Tel/Fax: + 86-411-84986112; E-mail: anhuilu@dlut.edu.cn This work was supported by the National Natural Science Foundation of China $(21225312,21403027)$. 
the irreversible leaching of metals from the carbon will inevitably reduce catalytic activity and stability, which is attributed to the inertness of the carbon surface [23]. It has been reported that the introduction of nitrogen functional groups onto the carbon is beneficial for increasing the dispersion and stability of Pd nanoparticles [24]. Su's group [25] studied the impact of CNTs functionalized by $\mathrm{NH}_{3}$ at $400-600{ }^{\circ} \mathrm{C}$ on the morphology of Pd-PVA nanoparticles, and reported that smaller Pd nanoparticles with the mean size of $2.7 \pm 0.6 \mathrm{~nm}$ were obtained with the N-CNT support as compared with those on the Pd/CNTs catalyst $(3.6 \pm 0.6 \mathrm{~nm})$, which led to improved activity in benzyl alcohol oxidation. It was suggested that doping with electron-rich nitrogen atoms modified the surface chemistry of the carbon materials for the adsorption of the metal nanoparticles [26]. However, it is still a problem to prepare uniform metal nanoparticles over carbon supports without using a protective agent. Yang's group [27] prepared Pd nanoparticles supported on nitrogen-doped mesoporous carbon with the metal size range of 3-10 $\mathrm{nm}$ by an impregnation method, which was due to the heterogeneity of the carbon surface. Hence, it is still necessary to develop a catalyst preparation for uniform $\mathrm{Pd}$ nanoparticles by a facile preparation method.

Based on our previous study using monodispersed polybenzoxazine-based carbon nanospheres, these carbon nanospheres can achieve a homogeneous incorporation of nitrogen into the carbon, and act as a good support for the preparation of an active catalyst for aerobic benzyl alcohol oxidation [28]. In this work, carbon nanosphere supported Pd nanocatalysts were prepared by the direct pyrolysis of the metal precursor impregnated on the polybenzoxazine-based polymer nanospheres. Particular attention was paid to investigating the effect of the support properties on the dispersion and stability of the active metal, and the preparation conditions needed to obtain outer surface Pd nanoparticles by controlling the impregnation conditions. The catalysts were tested with liquid phase benzyl alcohol oxidation at $80{ }^{\circ} \mathrm{C}$ under oxygen $(0.1$ $\mathrm{MPa}$ ). Water was used as the solvent without a base additive. The recyclability of the catalyst was also studied.

\section{Experimental}

\subsection{Chemicals}

Resorcinol (99.5\%), formaldehyde (37 wt\%, formalin), toluene (99.0\%), benzyl alcohol (99.0\%), benzaldehyde (99.0\%), and benzoic acid (99.0\%) were purchased from Tianjin Kermel Chemical Reagent Co., Ltd. Pluronic F127 and 1,6-diaminohexane (DAH, 99.0\%) were purchased from Fluka. All the chemicals were used as purchased without further purification.

\subsection{Catalyst preparation}

The monodispersed polybenzoxazine-based polymer nanospheres (denoted PBFS) were prepared according to a reported paper [28]. Resorcinol was first dissolved in deionized water with vigorous stirring at $24{ }^{\circ} \mathrm{C}$, and then F127 and formalde- hyde were added to form a clear solution. After the addition of $\mathrm{DAH}$, the clear solution became a white colloid within a minute. The resulting solution was heated to $80{ }^{\circ} \mathrm{C}$ accompanied with vigorous stirring for $18 \mathrm{~h}$. The PBFS product was obtained after washing with water. The carbon nanospheres (denoted CBFS) were obtained by the carbonization of PBFS at $500{ }^{\circ} \mathrm{C}$ under argon. The synthesis procedure of the PBFS loaded Pd catalyst was as follows. A suspension of PBFS (50 mg) dispersed in water was added into a $\mathrm{H}_{2} \mathrm{PdCl}_{4}$ aqueous solution ( $2 \mathrm{mmol} / \mathrm{L}$ ) and stirred at $25{ }^{\circ} \mathrm{C}$. The mixture was separated by centrifugation and dried at $50^{\circ} \mathrm{C}$ for $12 \mathrm{~h}$. The Pd loaded sample was thermally treated at a desired temperature $\left(500,600,700\right.$, and $\left.800{ }^{\circ} \mathrm{C}\right)$ under argon for $2 \mathrm{~h}$, and the samples were named as Pd@PBFS-500, Pd@PBFS-600, Pd@PBFS-700, and Pd@PBFS-800. Finally, the catalyst was thoroughly washed with deionized water to remove chloride ions. The catalyst preparation procedure of the CBFS supported Pd catalyst was the same as that of the PBFS supported catalyst, and the catalyst named as Pd@CBFS-500 was thermally treated at $500{ }^{\circ} \mathrm{C}$ under argon.

\subsection{Catalytic test}

The catalytic test was carried out in a glass reactor with a volume of $13 \mathrm{~mL}$. $\mathrm{O}_{2}$ was bubbled into the reactor under atmospheric pressure from a balloon for $20 \mathrm{~min}$ to eliminate trapped residual air. The desired amount of the benzyl alcohol $(0.1 \mathrm{~mol} / \mathrm{L})$ substrate and catalyst were added. Next, the reactor was sealed and heated to $80{ }^{\circ} \mathrm{C}$ under vigorous stirring. After the reaction, the product mixture was extracted with toluene for analysis. The molar ratio of the substrate to Pd was 100. The reactants and products were analyzed by a GC 7890F gas chromatograph equipped with a flame ionization detector (FID). Quantification of the products was done by using the external calibration method. The carbon balance in liquid phase was $>95 \%$ for all the tests.

\subsection{Characterization}

Transmission electron microscopy (TEM) images of the samples were obtained with a FEI Tecnai G220S-Twin electron microscope equipped with a cold field emission gun. Samples were prepared by dropping a few drops of a suspension containing the sample in ethanol onto a holey carbon grid with a pipette. The thermal decomposition behavior of the sample was monitored using a thermal analyzer (Netzsch STA 449 F3) from 40 to $800{ }^{\circ} \mathrm{C}$ with a heating rate of $10{ }^{\circ} \mathrm{C} / \mathrm{min}$ under nitrogen atmosphere. FTIR spectra were recorded using a Nicolet 6700 FTIR spectrometer at a resolution of $2 \mathrm{~cm}^{-1}$ from 4000 to $640 \mathrm{~cm}^{-1}$. The dispersion of $\mathrm{Pd}$ on the support was determined by the CO pulse method at $30{ }^{\circ} \mathrm{C}$ using an AutoChem 2920 instrument (Micromeritics, USA). Prior to the measurement, the sample was subjected to a pretreatment involving exposure to He flow for $1 \mathrm{~h}$ at $250{ }^{\circ} \mathrm{C}$, followed by $5 \mathrm{vol} \% \mathrm{CO} / \mathrm{He}$ purge for $0.5 \mathrm{~h}$ at $250{ }^{\circ} \mathrm{C}$. The $\mathrm{CO}$ adsorption capacity was then obtained from the number of pulses required to saturate the surface of the catalyst at $30{ }^{\circ} \mathrm{C}$. 


\section{Results and discussion}

\subsection{Support effect}

The structure and surface chemistry of the support have a crucial role in determining Pd particle size, size distribution, and metal-support interaction of heterogeneous catalysts. Here, we investigated the support effect on the catalytic performances of $\mathrm{Pd}$ nanocatalysts by impregnating the $\mathrm{H}_{2} \mathrm{PdCl}_{4}$ precursor on two different supports (PBFS and CBFS) followed by a thermal treatment under Ar. A series of characterization methods were used to explore the structural features of the supports and catalysts.

FTIR spectroscopy is a very useful tool to characterize the surface functional groups of the PBFS and CBFS supports. In Fig. 1(a), the peak at $\sim 1171 \mathrm{~cm}^{-1}$ is the $\mathrm{C}-\mathrm{N}$ stretching vibration of benzoxazine in the FTIR spectrum of the PBFS, and the peaks at $\sim 1238$ and $\sim 1110 \mathrm{~cm}^{-1}$ were attributed to the $\mathrm{C}-\mathrm{O}-\mathrm{C}$ stretching originating from the stretching of the aromatic ether. In the spectrum of the CBFS sample, the peak at $1230 \mathrm{~cm}^{-1}$ was attributed to the $\mathrm{C}-\mathrm{O}-\mathrm{C}$ stretching. The peak at $\sim 3210 \mathrm{~cm}^{-1}$ can be assigned to $-\mathrm{OH}$ stretching of the PBFS, but the intensity of this peak was obviously weaker for the CBFS, as seen in Fig. 1(b). The results revealed that the PBFS support possessed more nitrogen-containing and oxygen-containing functional groups than the CBFS support. These functional groups play a positive role in stabilizing Pd nanoparticles.

To verify that these functional groups stabilized the active metal species, we prepared Pd nanocatalysts on the PBFS and CBFS supports by immersing the support in the $\mathrm{H}_{2} \mathrm{PdCl}_{4}$ precursor solution under stirring at room temperature. To determine whether the metal precursor was loaded onto the support, the mixture after stirring for $1 \mathrm{~h}$ was centrifuged, and the supernatant solution was treated with $\mathrm{NaBH}_{4}$ solution. A Tyndall effect was observed in the solution from the Pd@CBFS mixture indicating some $\mathrm{H}_{2} \mathrm{PdCl}_{4}$ remained in the solution. In contrast, this effect was not observed in the case of the Pd@PBFS solution under identical test conditions, indicating that the Pd precursor was loaded on PBFS within one hour. Further experiments showed that in the case of the Pd@CBFS mixture, a continuous stirring period of $6 \mathrm{~h}$ was required for the metal precursor to be loaded on the carbon support. It has been demonstrated that electron-rich nitrogen atoms can produce localized charge accumulation that act as coordination sites for Pd nanoparticles [29,30]. In the present study, PBFS containing more nitrogen atoms than CBFS [31] would have a
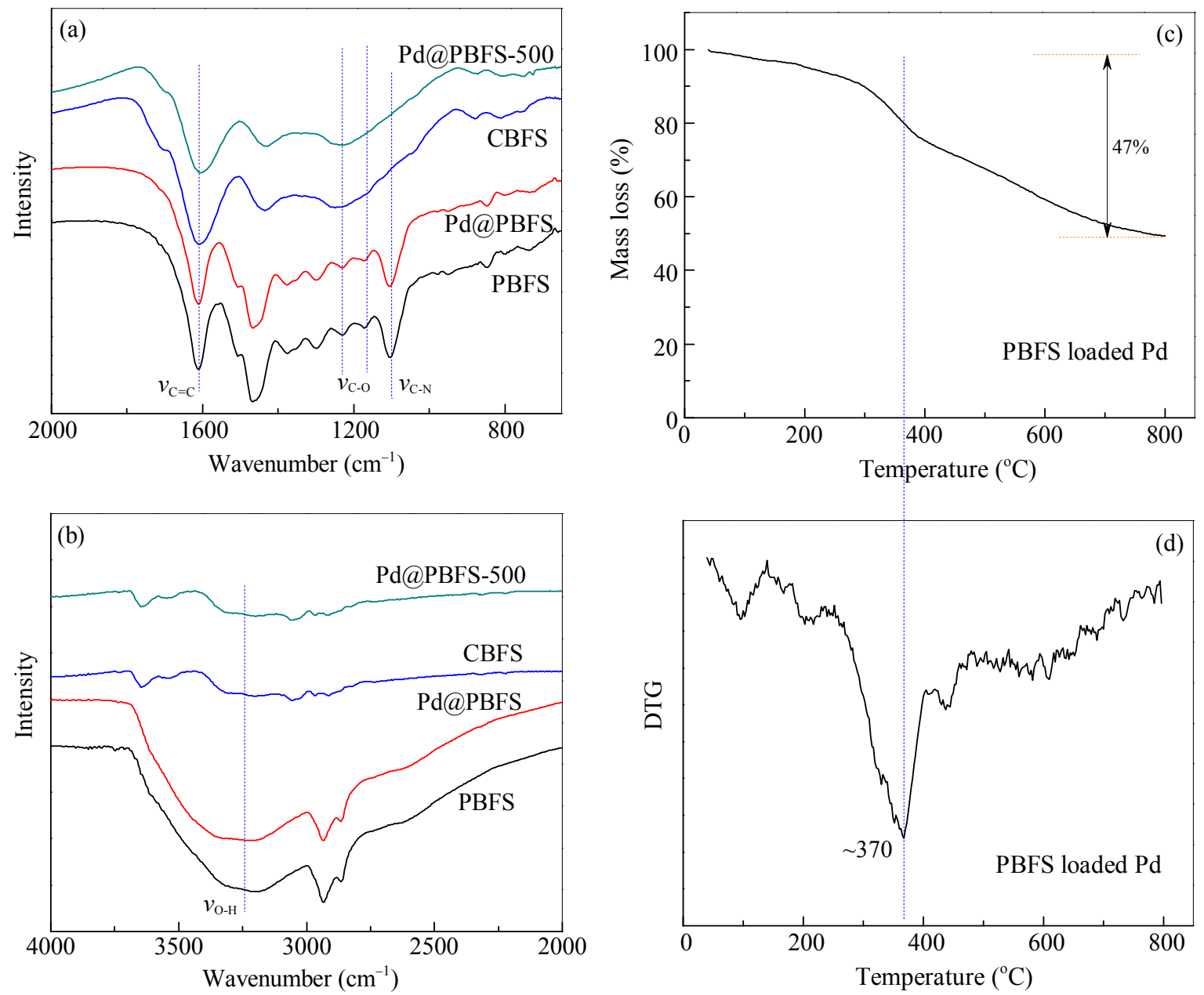

Fig. 1. FTIR spectra of PBFS, Pd@PBFS, CBFS, and Pd@PBFS-500 samples (a, b); TG (c) and DTG (d) curves of the PBFS loaded Pd precursor without thermal pretreatment. 
stronger interaction with the $\mathrm{H}_{2} \mathrm{PdCl}_{4}$ precursor [32-34]. To further understand this, it can be noted that the stability constants of the coordination compounds between $\mathrm{Pd}^{2+}$ and the ligands of $\mathrm{NH}_{3}, \mathrm{OH}^{-}$, and $\mathrm{Cl}^{-}$decrease in the order: $\mathrm{NH}_{3}>\mathrm{OH}^{-}>$ $\mathrm{Cl}^{-}$[35]. A larger coordination stability constant leads to a larger tendency to form a complex, which allows the forming of a stable complex. Therefore, $\mathrm{Pd}^{2+}$ ions preferentially interact with the nitrogen functional groups on the surface of PBFS support by a complexation interaction for stabilizing the metals [25]. As seen in Fig. 1, there were no distinct differences in the peak positions and peak intensities of the FTIR spectra of PBFS and Pd@PBFS, and Pd@PBFS-500 also showed the same peaks as CBFS, indicating that the support structure remained unchanged after the introduction of the metal.

A TG-DTG analysis was conducted under a nitrogen atmosphere in order to disclose the thermal behavior of the PBFS loaded Pd catalyst (Fig. 1(c), (d)). It can be seen that the sample exhibited a continuous mass loss from 40 to $800{ }^{\circ} \mathrm{C}$. The mass loss below $100{ }^{\circ} \mathrm{C}$ was attributed to the de-intercalation of $\mathrm{H}_{2} \mathrm{O}$, while the mass loss above $100{ }^{\circ} \mathrm{C}$ was mainly due to the decomposition of the functional groups on the support [36]. The TG and DTG curves displayed an obvious mass loss at $\sim 370{ }^{\circ} \mathrm{C}$, which was attributed to the decomposition of the surfactant F127 present on the nanosphere [37]. Therefore, in the following study, we mainly studied the carbon supported Pd catalysts which were obtained by a thermal treatment above $500{ }^{\circ} \mathrm{C}$. The structural features of the carbon supported Pd nanocatalyst (Pd@PBFS-500), and the Pd@CBFS-500 catalyst as a reference, were further characterized by TEM. The results are shown in Fig. 2 . Both catalysts were first thermally treated at $500{ }^{\circ} \mathrm{C}$. It was clearly observed that the supports were monodispersed carbon nanospheres with the mean size of $180 \mathrm{~nm}$. Fig. 2(a) shows that most of the Pd nanoparticles with a uniform size of $3 \mathrm{~nm}$ were highly dispersed on the support for the Pd@PBFS-500 sample, and no clear Pd aggregation was seen from a large area TEM observation (Fig. 2(b)). For the
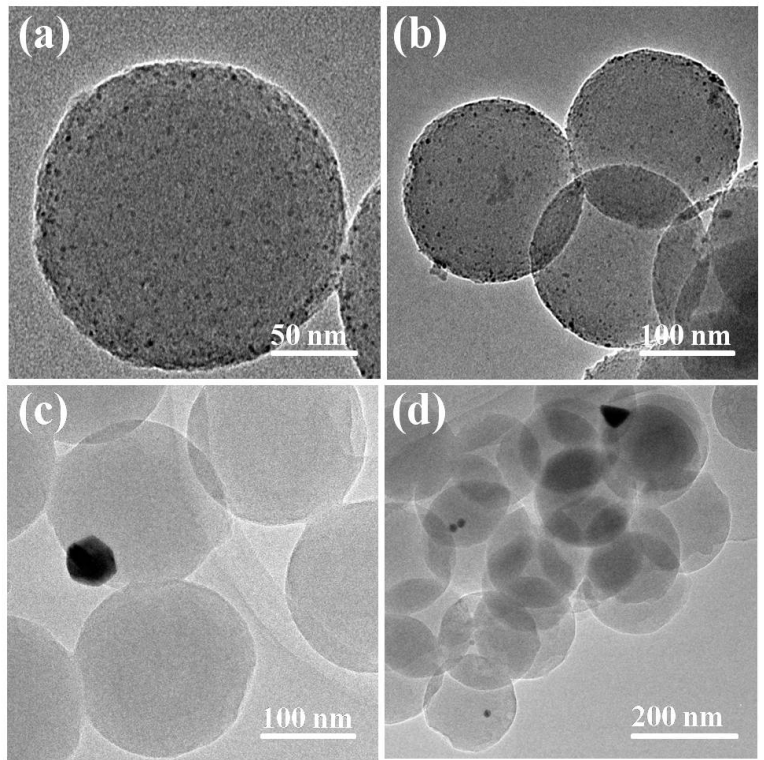

Fig. 2. TEM images of the catalysts. (a, b) Pd@PBFS-500; (c, d) Pd@CBFS-500.
Pd@CBFS-500 catalyst, Pd nanoparticles with a wide size distribution of 10 to $50 \mathrm{~nm}$ were obviously aggregated after the $500{ }^{\circ} \mathrm{C}$ thermal treatment (shown in Fig. 2(c), (d)). The poor metal dispersion of the Pd@CBFS-500 catalyst may be attributed to the weak interaction between the Pd nanoparticles and the CBFS support. The results indicated that PBFS is an effective support for the stabilization of Pd nanoparticles. Furthermore, the Pd dispersion, i.e., the fraction of exposed Pd on the catalyst, was determined by the $\mathrm{CO}$ adsorption method. The Pd dispersion of the Pd@PBFS-500 and Pd@CBFS-500 catalysts are determined to be $25 \%$ and $3 \%$, respectively. The results were consistent with TEM measurements, revealing that the Pd@PBFS-500 catalyst possessed good metal dispersion.

The catalytic performances of the Pd@PBFS-500 and Pd@CBFS-500 catalysts were evaluated with benzyl alcohol oxidation under atmospheric oxygen at $80{ }^{\circ} \mathrm{C}$. The Pd@PBFS-500 catalyst exhibited a high conversion (>99\%) with a high selectivity to benzaldehyde (>99\%) within $1 \mathrm{~h}$. Under the identical reaction condition, the Pd@CBFS-500 catalyst only showed a conversion of $8 \%$ with the selectivity to benzaldehyde of above $99 \%$. No detectable acid was found in the product for both catalysts, which indicated benzyl alcohol was selectively converted to benzaldehyde under the mild reaction conditions. The Pd@PBFS-500 catalyst with the uniform metal size of $3 \mathrm{~nm}$ showed an excellent catalytic performance. This result is consistent with that from the literatures [9,38,39]. In contrast, the Pd@CBFS-500 catalyst, which has a wide size distribution (10-50 nm) with aggregated Pd nanoparticles, exhibited a low conversion. The aerobic oxidation of benzyl alcohol to benzaldehyde is not a structure sensitive reaction, and the reaction activity mainly depended on the mean size of the $\mathrm{Pd}$ nanoparticles $[40,41]$. The catalytic results reveal that the PBFS is a good support for the preparation of active $\mathrm{Pd}$ nanocatalysts for benzyl alcohol oxidation.

\subsection{Influence of the catalyst preparation conditions}

The above experiments have shown that PBFS is an efficient support than CBFS for loading Pd nanoparticles. Using this support, we further optimized the preparation conditions for enhancing the catalytic performance. During the catalyst preparation, the active metals enter the nanosphere from outside to inside, and the Pd nanoparticles located deep inside the nanosphere are difficult to access by the substrate. Thus, we wanted to manipulate the Pd nanoparticles to get them located near or on the nanosphere outer surface by controlling the metal loading conditions to improve the utilization of the active metal.

From our previous results and analysis, it is known that the Pd crystallites preferentially interact with the nitrogen-functional groups on the support, and we explored the relationship between the metal loading and nitrogen content. The elemental analysis reveals that the PBFS has a nitrogen content of $3.7 \mathrm{wt} \%$. We suppose that the nitrogen atoms are uniformly dispersed inside the nanosphere support, and one metal atom interacts with one nitrogen atom on the support. The number of nitrogen atoms on the nanosphere outer surface can give a maximum Pd loading of $2 \mathrm{wt} \%$ from the calculation. 
This indicated that most Pd nanoparticles would be formed near or on the nanosphere outer surface when the Pd loading is below 2 wt\%, while Pd nanoparticles would be present inside the nanosphere with a higher Pd loading. The catalytic activities of the catalysts with changing Pd loading from $0.2 \mathrm{wt} \%$ to 2 wt $\%$ were investigated (Fig. 3(a)). The catalytic activity reached a conversion of $78 \%$ after $30 \mathrm{~min}$ when the Pd loading was increased from $0.2 \mathrm{wt} \%$ to $1 \mathrm{wt} \%$. A possible cause of this is the increased Pd nanoparticles on the support. However, a slight increase of the activity occurred when the metal loading was further increased to $2 \mathrm{wt} \%$, confirming that the active metal catalyzed the reaction under this reaction condition. Therefore, a low metal loading of 1 wt $\%$ seems adequate for a high activity under this reaction condition.

The metal loading time was also considered to be an important factor influencing the location and dispersion of the active metals on the support, and the catalytic activities of the catalysts prepared by controlling the metal loading time were further studied using the Pd loading of $1 \mathrm{wt} \%$. The PBFS support was immersed in the $\mathrm{H}_{2} \mathrm{PdCl}_{4}$ solution and stirred for various times at room temperature, while other preparation conditions were kept identical. Then, the collected material was thermally treated at $500{ }^{\circ} \mathrm{C}$ under $\mathrm{Ar}$ and converted to the final catalyst. The catalytic activities of these catalysts prepared using various metal loading times were evaluated under identical reaction conditions. The results are shown in Fig. 3(b). The catalyst prepared with the loading time of $1 \mathrm{~h}$ showed a higher conversion compared to the one with $0.5 \mathrm{~h}$. However, with further increase in the loading time, the conversion dropped. It was suspected that the metal precursor may gradually diffuse into the nanosphere support from the external surface to the interior with the increase of the loading time. It may be difficult for the substrate to access the Pd nanoparticles located deep in the interior of the support, leading to a lower activity. Therefore, the metal loading time of $1 \mathrm{~h}$ is a suitable period for the preparation of a catalyst with high activity due to the easily accessible Pd nanoparticles in a short contact time.

Under the optimized metal loading conditions, another important factor was further investigated, namely, the thermal

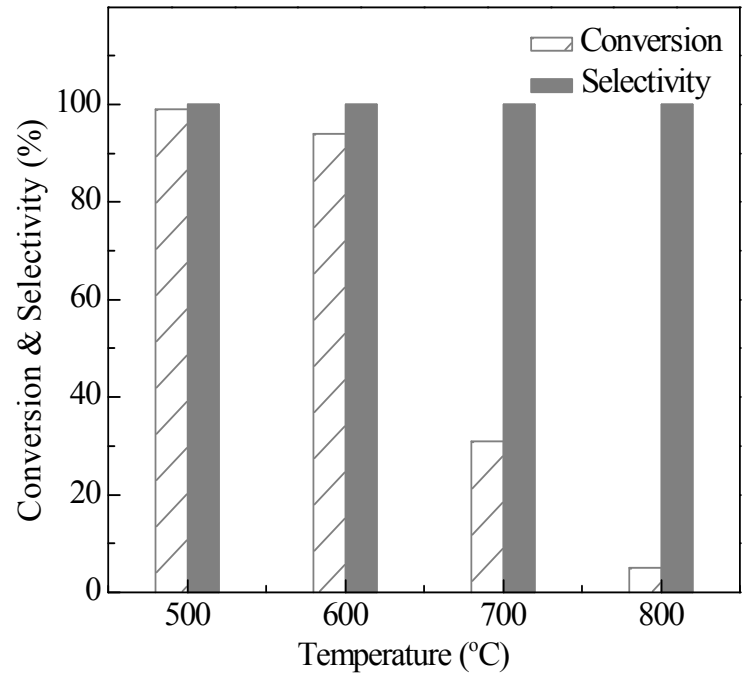

Fig. 4. Catalytic activity of the Pd@PBFS catalysts after thermal treatment at different temperatures under argon. Reaction time was $2 \mathrm{~h}$.

treatment temperature. The catalytic activities of Pd@PBFS catalysts using thermal treatment at different temperatures were evaluated, and shown in Fig. 4. The Pd@PBFS-500 catalyst exhibited a high conversion of $>99 \%$. The catalytic activity of Pd@PBFS-600 catalyst still reached the conversion of 94\%. These results revealed that the active metals basically maintained their catalytic activity after a thermal treatment at 600 ${ }^{\circ} \mathrm{C}$, and the good thermal stability was attributed to the complexation interaction between the metal and support. However, the catalytic activity of the Pd@PBFS-700 and Pd@PBFS-800 catalysts decreased to $31 \%$ and $8 \%$, respectively. From the TEM images of the Pd@PBFS-700 sample (Fig. 5), it can be clearly seen that the size of Pd nanoparticles has increased to 5 to $10 \mathrm{~nm}$, and a few large particles with the size of $20 \mathrm{~nm}$ were observed. The lower catalytic activity of Pd@PBFS-700 and Pd@PBFS-800 would be due to metal agglomeration. The results revealed that the catalytic performance of the catalyst was influenced by the thermal treatment temperature, and the optimum temperature was $500{ }^{\circ} \mathrm{C}$.
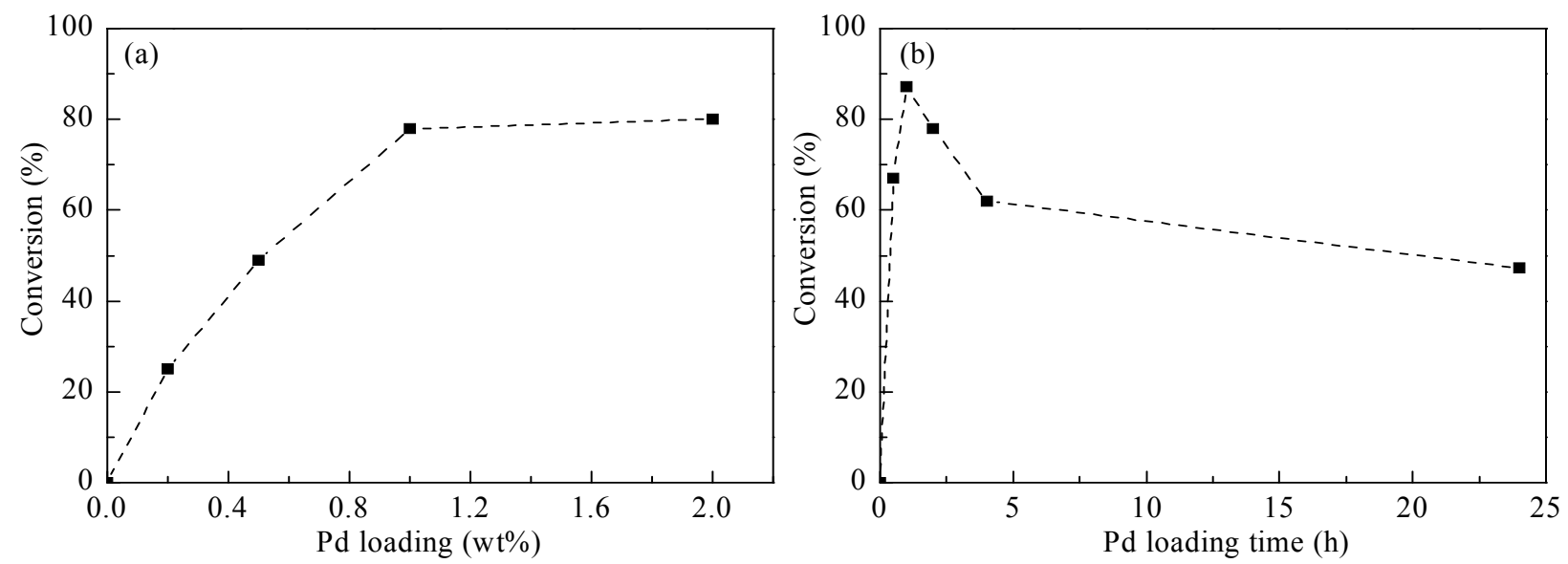

Fig. 3. Catalytic activities of Pd@PBFS-500 catalysts. (a) Various Pd loading with loading time of 2 h; (b) Various loading times with Pd loading of 1 wt $\%$. Reaction time was $30 \mathrm{~min}$. 


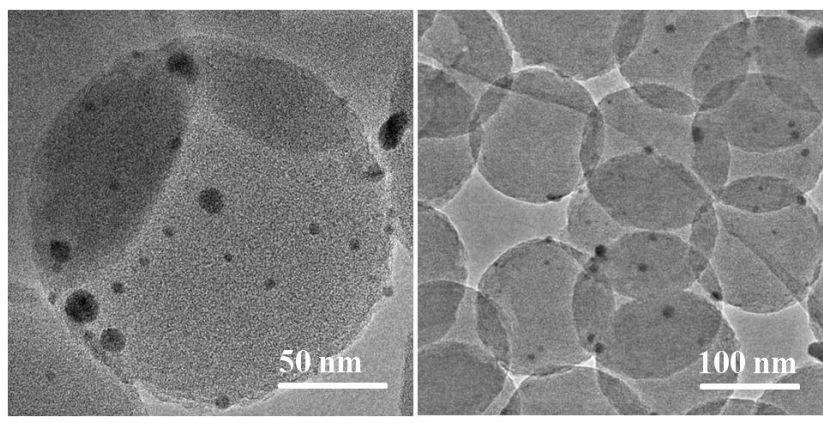

Fig. 5. TEM images of the Pd@PBFS-700 catalyst.

The results showed that the sample Pd@PBFS-500 with the Pd loading of $1 \mathrm{wt} \%$ and loading time of $1 \mathrm{~h}$ was the most active catalyst. In a further comparison with other carbon supported Pd catalysts under similar reaction conditions for benzyl alcohol oxidation (see Table 1), the Pd@PBFS-500 catalyst was shown to exhibit a fast reaction rate due to the easily accessible active Pd sites, and it showed a high selectivity to benzaldehyde (>99\%).

\subsection{Recycling stability of the catalyst}

The recyclability and stability of the catalyst are important factors in industrial application. Hence, the recycling of the Pd@PBFS-500 catalyst was studied. The catalyst was recovered after each reaction run, washed with water and alcohol, dried at $50{ }^{\circ} \mathrm{C}$, and reused in a subsequent catalytic run. A small loss of catalyst was ignored during the recycling test. Fig. 6 shows that the Pd@PBFS-500 catalyst exhibited good reusability in the initial three runs, but the conversion dropped after recycling for eight runs. Similar results were obtained with the catalysts treated at higher temperatures. As shown in Fig. 7, the TEM image of the spent Pd@PBFS-500 catalyst after five runs showed that the size and shape of the Pd nanoparticles remained almost unchanged. This indicated the good stability of the catalyst under the mild reaction conditions. Furthermore, the experiment to determine whether there existed the leaching of $\mathrm{Pd}$ nanoparticles during the reaction, showed negligible conversion of benzyl alcohol when the liquid filtrate was used as catalyst instead of the solid catalyst for the further reaction. This indicated the good stability of the catalyst during the reaction, which provides evidence of the complexation interaction between the metal and support. In addition, it is noteworthy that the conversion slightly dropped during the recycle, while the selectivity towards benzaldehyde was retained at $>99 \%$ under the present mild reaction conditions. Moreover, the catalyst can be easily regenerated by a simple calcination treatment at $200{ }^{\circ} \mathrm{C}$ under air after several runs. This was because adsorbed organic species on the surface of Pd nanoparticles can be eliminated by a simple calcination [46]. In addition, the Pd@CBFS-500 catalyst also showed good stability.

Table 1

Comparison of various carbon supported Pd catalysts for benzyl alcohol oxidation to benzaldehyde.

\begin{tabular}{|c|c|c|c|c|c|c|c|c|c|}
\hline Catalyst & $T /{ }^{\circ} \mathrm{C}$ & $P / \mathrm{MPa}$ & Oxidant & Solvent & Reaction time (h) & Conversion (\%) & Selectivity (\%) & TOF $\left(\mathrm{h}^{-1}\right)$ & Ref. \\
\hline Pd@PBFS-500 & 80 & 0.1 & $\mathrm{O}_{2}$ & $\mathrm{H}_{2} \mathrm{O}$ & 0.5 & 87 & $>99$ & $690^{a}$ & this study \\
\hline $\mathrm{Pd} / \mathrm{CB}$ & 80 & 0.1 & $\mathrm{O}_{2}$ & $\mathrm{H}_{2} \mathrm{O}$ & 2 & 10 & $>99$ & $5^{b}$ & [28] \\
\hline $\mathrm{Pd} / \mathrm{AC}$ & 60 & 0.15 & $\mathrm{O}_{2}$ & $\mathrm{H}_{2} \mathrm{O}$ & 3 & 18 & 91 & $30^{\mathrm{a}}$ & [42] \\
\hline $\mathrm{Pd} / \mathrm{AC}$ & 60 & 0.15 & $\mathrm{O}_{2}$ & $\mathrm{H}_{2} \mathrm{O}$ & 0.25 & 0.75 & $>99$ & $15^{\mathrm{a}}$ & [43] \\
\hline Pd/CMK-3 & 80 & 0.1 & $\mathrm{O}_{2}$ & 1,4-dioxane & 1 & 55 & 80 & $234^{b}$ & [44] \\
\hline $\mathrm{Pd} / \mathrm{CNTs}$ & 100 & 0.2 & $\mathrm{O}_{2}$ & $\mathrm{H}_{2} \mathrm{O}$ & - & - & 74 & $32.2^{c}$ & [45] \\
\hline Pd@hmC & 80 & 0.1 & $\mathrm{O}_{2}$ & $\mathrm{H}_{2} \mathrm{O}, \mathrm{K}_{2} \mathrm{CO}_{3}$ & 1 & 48 & 77 & $2940^{a}$ & [3] \\
\hline Pd/Fe@C & 80 & 0.1 & $\mathrm{O}_{2}$ & $\mathrm{H}_{2} \mathrm{O}, \mathrm{K}_{2} \mathrm{CO}_{3}$ & 25 & 63 & 67 & $5^{b}$ & [4] \\
\hline
\end{tabular}

a Obtained by the number of converted benzyl alcohol molecules on surface Pd atoms divided by the reaction time.

${ }^{b}$ Calculated on the basis of the total metal using the molar ratio of the converted substrate over the catalyst divided by the reaction time.

${ }^{c}$ Calculated in terms of conversion per $\mathrm{m}^{2}$ exposed $\mathrm{Pd}$ metal per hour.
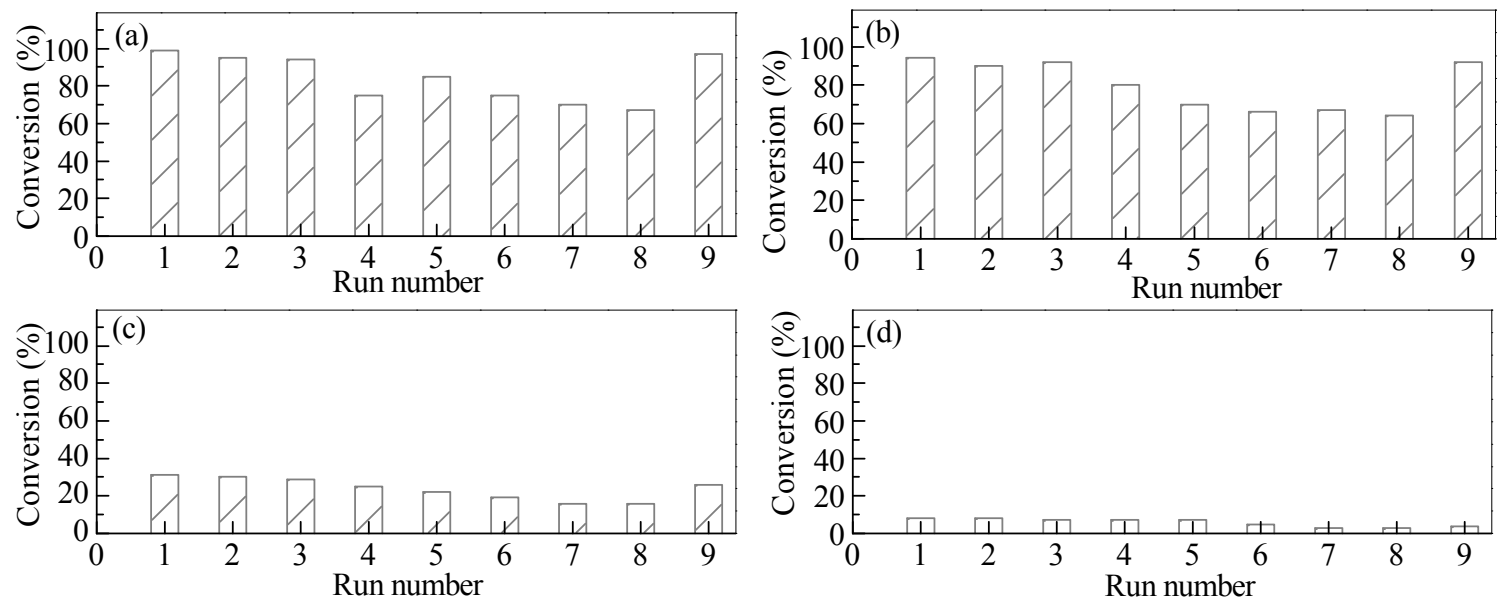

Fig. 6. Reusability and regeneration of Pd@PBFS-T catalysts with different thermal treatment conditions. (a) Pd@PBFS-500; (b) Pd@PBFS-600; (c) Pd@PBFS-700; (d) Pd@CBFS-500. Each catalyst was run for 8 cycles, and the 9th run was carried out with the regenerated catalyst after calcination. 




Fig. 7. TEM image of the spent Pd@PBFS-500 catalyst after five runs.

These results revealed that the carbon nanosphere support is benefial for enhancing the resistance to Pd loss.

\section{Conclusions}

We prepared nitrogen-doped carbon nanosphere supported Pd catalysts by the direct pyrolysis of the metal precursor impregnated on polybenzoxazine-based polymer nanospheres under Ar atmosphere and used these for benzyl alcohol oxidation. The Pd@PBFS-500 catalyst with a uniform metal particle size of $3 \mathrm{~nm}$ exhibited the higher conversion of $>99 \%$ within 1 h compared to the Pd@CBFS-500. The highest catalytic activity of the Pd@PBFS-500 catalyst was obtained when the Pd loading time was $1 \mathrm{~h}$ with a Pd loading of $1 \mathrm{wt} \%$. The complexation interaction between the metal and support plays a crucial role for the size distribution and stability of the Pd nanoparticles. Our preparation method for a Pd nanocatalyst provides an alternative for making a high performance alcohol oxidation catalyst, and can be used for other reactions.

\section{References}

[1] Mallat T, Baiker A. Chem Rev, 2004, 104: 3037
[2] Enache D I, Edwards J K, Landon P, Solsona-Espriu B, Carley A F, Herzing A A, Watanabe M, Kiely C J, Knignt D W, Hutchings G J. Science, 2006, 311: 362

[3] Harada T, Ikeda S, Hashimoto F, Sakata T, Ikeue K, Torimoto T, Matsumura M. Langmuir, 2010, 26: 17720

[4] Zhang H, Liu Y, Zhang X G. Chin J Catal (张海, 刘英, 张勋高. 催化 学报), 2011, 32: 1693

[5] Poliakoff M, Fitzpatrick J M, Farren T R, Anastas P T. Science, 2002, 297: 807

[6] Astruc D, Lu F, Aranzaes J R. Angew Chem Int Ed, 2005, 44: 7852

[7] Zhang P F, Gong Y T, Li H R, Chen Z R, Wang Y. Nature Commun, 2013, 4: 1593

[8] Liu J, Yang H Q, Kleitz F, Chen Z G, Yang T Y, Strounina E, Lu G Q, Qiao S Z. Adv Funct Mater, 2012, 22: 591

[9] Li C L, Zhang Q H, Wang Y, Wan H L. Catal Lett, 2008, 120: 126

[10] Chan-Thaw C E, Villa A, Prati L, Thomas A. Chem Eur J, 2011, 17: 1052

[11] Lu J L, Fu B S, Kung M C, Xiao G M, Elam J W, Kung H H, Stair P C. Science, 2012, 335: 1205

[12] Samanta A, Devi R N. ChemCatChem, 2013, 5: 1911

[13] Keresszegi C, Ferri D, Mallat T, Baiker A. J Phys Chem B, 2005, 109: 958

[14] Grunwaldt J-D, Caravati M, Baiker A. J Phys Chem B, 2006, 110: 9916

[15] Zhang H Y, Xie Y, Sun Z Y, Tao R T, Huang C L, Zhao Y F, Liu Z M. Langmuir, 2011 27: 1152

[16] An G, Ahn H, De Castro K A, Rhee H. Synthesis, 2010: 477

[17] Karimi B, Zamani A, Abedi S, Clark J H. Green Chem, 2009, 11: 109

[18] Auer E, Freund A, Pietsch J, Tacke T. Appl Catal A, 1998, 173: 259

[19] Yang K, Xing B S. Chem Rev, 2010, 110: 5989

[20] Derylo-Marczewska A, Goworek J, Świątkowski A, Buczek B. Carbon, 2004, 42: 301

[21] Liang C D, Li Z J, Dai S. Angew Chem Int Ed, 2008, 47: 3696

[22] Peng W C, Liu S Z, Sun H Q, Yao Y J, Zhi L J, Wang S B. J Mater Chem A, 2013, 1: 5854

[23] Balasubramanian K, Burghard M. Small, 2005, 1: 180

[24] Karimi B, Behzadnia H, Bostina M, Vali H. Chem Eur J, 2012, 18: S8634/1

[25] Arrigo R, Wrabetz S, Schuster M E, Wang D, Villa A, Rosenthal D, Girsgdies F, Weinberg G, Prati L, Schlögl R, Su D S. Phys Chem Chem Phys, 2012, 14: 10523

[26] Paraknowitsch J P, Thomas A, Antonietti M. J Mater Chem, 2010, 20: 6746

\section{Graphical Abstract}

Chin. J. Catal., 2015, 36: 612-619 doi: 10.1016/S1872-2067(14)60274-6

Uniformly dispersed Pd nanoparticles on nitrogen-doped carbon nanospheres for aerobic benzyl alcohol oxidation

Yan Hao, Shuai Wang, Qiang Sun, Lei Shi, An-Hui Lu*

Dalian University of Technology

An easy procedure was presented for the preparation of uniformly dispersed and stable Pd nanoparticles supported on carbon nanospheres by the direct pyrolysis of the metal precursor impregnated on polybenzoxazine-based polymer nanospheres. The catalyst was used for benzyl alcohol oxidation.




[27] Wang B, Lin M, Ang T P, Chang J, Yang Y H, Borgna A. Catal Commun, 2012, 25: 96

[28] Wang S, Li W C, Hao G P, Hao Y, Sun Q, Zhang X Q, Lu A H. J Am Chem Soc, 2011, 133: 15304

[29] Abate S, Arrigo R, Schuster M E, Perathoner S, Centi G, Villa A, Su D S, Schlögl R. Catal Today, 2010, 157: 280

[30] Abate S, Freni M, Arrigo R, Schuster M E, Perathoner S, Centi G. ChemCatChem, 2013, 5: 1899

[31] Wang S, Li W C, Zhang L, Jin Z Y, Lu A H.J Mater Chem A, 2014, 2: 4406

[32] Villa A, Wang D, Spontoni P, Arrigo R, Su D S, Prati L. Catal Today, 2010, 157: 89

[33] Wu G J, Wang X M, Guan N J, Li L D. Appl Catal B, 2013, 136-137: 177

[34] Yan Y B, Chen Y T, Jia X L, Yang Y H. Appl Catal B, 2014, 156-157: 385

[35] Högfeldt E. Stability Constants of Metal-Ion Complexes, Part A: Inorganic Ligands. 2nd Ed. Pergamon Press, 1982. 44

[36] Hirose T, Fujino T, Fan T X, Endo H, Okabe T, Yoshimura M. Car- bon, 2002, 40: 761

[37] Lu A H, Spliethoff B, Schüth F. Chem Mater, 2008, 20: 5314

[38] Li F, Zhang Q H, Wang Y. Appl Catal A, 2008, 334: 217

[39] Chen J, Zhang Q H, Wang Y, Wan H L. Adv Synth Catal, 2008, 350: 453

[40] Ferri D, Mondelli C, Krumeich F, Baiker A. J Phys Chem B, 2006, 110: 22982

[41] Ravat V, Nongwe I, Meijboom R, Bepete G, Coville N J. J Catal, 2013, 305: 36

[42] Dimitratos N, Villa A, Wang D, Porta F, Su D S, Prati L.J Catal, 2006, 244: 113

[43] Villa A, Janjic N, Spontoni P, Wang D, Su D S, Prati L. Appl Catal A, 2009, 364: 221

[44] Harada T, Ikeda S, Miyazaki M, Sakata T, Mori H, Matsumura M. J Mol Catal A, 2007, 268: 59

[45] Villa A, Plebani M, Schiavoni M, Milone C, Piperopoulos E, Galvagno S, Prati L. Catal Today, 2012, 186: 76

[46] Hao Y, Hao G P, Guo D C, Guo C Z, Li W C, Li M R, Lu A H. ChemCatChem, 2012, 4: 1595

\title{
掺氮纳米炭球担载高分散钯纳米催化剂的制备及其苯甲醇氧化性能
}

\author{
郝 燕, 王帅, 孙蓄, 石 磊, 陆安慧 ${ }^{*}$ \\ 大连理工大学化工学院, 精细化工国家重点实验室, 辽宁大连116024
}

\begin{abstract}
摘要: 负载型贵金属纳米催化剂中的金属纳米粒子易发生团聚或流失, 因此提高金属活性组分的分散性和稳定性很重要。我们报 道了一种制备高分散钯纳米催化剂的方法, 通过浸泡法将氯钯酸前驱体负载到苯并噁溙聚合物上, 再经过惰性气氛一步热解得到 纳米炭球担载钯催化剂. 催化剂性能通过温和条件下苯甲醇氧化反应进行评价. 经过 $500{ }^{\circ} \mathrm{C}$ 热处理制备的催化剂, 从TEM图可以 看出Pd纳米粒子均匀分散在载体上, 尺寸大小约为 $3 \mathrm{~nm}$, 这是由于载体和钯活性组分的配位作用有利于提高钯纳米粒子的分散性 和稳定性. 通过调控金属负载量及负载时间, 尽可能地实现活性组分分布在载体外表面,制备的催化剂上最高TOF为 $690 \mathrm{~h}^{-1}$. 此 催化剂同时具有较好的循环稳定性, 失活后的催化剂经过 $200^{\circ} \mathrm{C}$ 焙烧即可实现再生.
\end{abstract}

关键词: 钯; 纳米炭球; 醇氧化; 循环稳定性

收稿日期: 2014-11-06. 接受日期: 2014-12-22. 出版日期: 2015-04-20.

*通讯联系人. 电话/传真: (0411)84986112; 电子信箱: anhuilu@dlut.edu.cn

基金来源：国家自然科学基金(21225312, 21403027).

本文的英文电子版由Elsevier出版社在ScienceDirect上出版(http://www.sciencedirect.com/science/journal/18722067). 